of $\mathrm{RuL}_{3}{ }^{2+}$ is sensitive to solvent environment; consequently, the lifetime or emission maxima can, perhaps, in conjunction with laser beam probing of the interface region as a function of polarizing potential, produce some detail concerning the interface structure. In that circumstance where an amphophilic $\mathrm{Ru}$ complex can be totally adsorbed at the interface region, the problem of separating bulk from interface Ru complex would be minimized.

Acknowledgment. Support of the Army Research Office (Grant No. 8AAL-03-86-K-0040) is gratefully acknowledged.

\title{
Stabilization of Cadmium Selenide Molecular Clusters in Zeolite Y: EXAFS and X-ray Diffraction Studies
}

\author{
Karin Moller, ${ }^{1 \mathrm{a}}$ Mike M. Eddy ${ }^{1 \mathrm{~b}}$ Galen D. Stucky, ${ }^{*, 1 \mathrm{~b}}$ Norman Herron, ${ }^{1 \mathrm{c}}$ and \\ Thomas Bein*,1a \\ Contribution from the Department of Chemistry, University of New Mexico, Albuquerque, \\ New Mexico 87131, Department of Chemistry, University of California, Santa Barbara, \\ California 93106, and the Central Research and Development Department, ${ }^{\dagger}$ E. I. du Pont de \\ Nemours \& Co., Wilmington, Delaware 19898. Received July 13, 1988
}

\begin{abstract}
Small ensembles of CdSe have been synthesized within the cage system of zeolite $\mathrm{Y}$ via ion exchange with Cd(II) and subsequent treatment with $\mathrm{H}_{2} \mathrm{Se}$. Cluster size and geometrical arrangements could be determined by comprehensive analysis of Cd- and Se-edge EXAFS data as well as synchroton X-ray powder diffraction and model calculations. The uptake of Se by the zeolite and bond formation to cadmium ions with a bond length of $2.60 \AA$ are clearly evident from EXAFS data of both absorption edges. The CdSe molecular clusters are stabilized at ambient conditions through strong interactions with the zeolite host. Rietveld analysis and EXAFS results indicate the presence of $70 \%$ of the cadmium ions at $\mathrm{SI}^{\prime}$ and $30 \%$ at SIII. Se,O-bridged cadmium dimers and $\mathrm{Cd}_{4} \mathrm{O}_{4}$ cubes are formed in the sodalite unit. Cadmium ions present in 12-ring windows are coordinated to one Se and additional oxygen atoms. Small amounts of Se helical chains and CdSe clusters are also detected.
\end{abstract}

Semiconductor particles are known to change their electronic, optical, and photochemical properties with particle size. Neither bulk nor molecular properties are encountered in the size range between $\sim 10$ and $50 \mathrm{~A}$. Wider electronic band caps and appearance of new, discrete absorption peaks in the electronic spectra of semiconductor "clusters" in this size range have been interpreted as quantum size effects and exciton formation..$^{2-4}$ The synthesis of well-defined semiconducting clusters with homogeneous morphology and size distribution is a prerequisite for understanding the physical origin of these effects. Classical preparation methods for these clusters include wet colloidal techniques, ${ }^{5-9}$ growth in dielectric glassy matrices, ${ }^{10}$ or growth in polymers. ${ }^{11}$ Characterization of cluster size and structure is often difficult to accomplish, especially with cluster sizes smaller than about $20 \AA$. Particle sizes are usually nonuniform, and agglomeration of individual particles often occurs. ${ }^{12}$ Thus the effect of particle size on optical and other properties is obscured.

In recent papers we reported an alternative method to stabilize well-defined semiconductor clusters that are much smaller than those typically formed by classical colloidal techniques. Selenium species and cadmium sulfide ensembles were encapsulated in the crystalline pore structure of zeolite matrices. ${ }^{13,14}$ In this paper we present a structural study of closely related cadmium selenide clusters stabilized in zeolite $Y$. These clusters are composed of a few atoms only that strongly interact with the zeolite host such that their bonding must be considered completely distinct from that of the bulk solid and typical semiconductor clusters. The size domain of the intrazeolite CdSe ensembles compares with that of species produced in gas-phase molecular beam studies. However, the interaction with the zeolite allows us to stabilize these CdSe species in condensed phase at ambient conditions. We observed similar stabilization effects with palladium atoms in zeolites $X$ and $Y{ }^{15}$ Colloidal cadmium selenide is of interest for photosensitized electron-transfer reactions utilized for solar energy conversion and photocatalysis. ${ }^{16-18}$

\footnotetext{
${ }^{+}$Contribution No. 4967.
}

The constraints provided by the rigid, crystalline aluminosilicate framework of a zeolite offer a considerable improvement in size definition over other preparative environments. Zeolites consist of corner-sharing $\mathrm{AlO}_{4}$ and $\mathrm{SiO}_{4}$ tetrahedra connected such that well-defined cavities and channels are formed (see Figure 1). Other metal cations can be introduced by ion exchange of the sodium ions present in the original material. The intrazeolite location of these cations is limited to sites close to framework oxygens that can fulfill the coordination requirements of the cation in question, as shown in Figure 1 for zeolite $Y$. Sodalite subunits are connected via six-ring windows to form the large supercages

(1) (a) University of New Mexico. (b) University of California. (c) Du Pont Co.

(2) Brus, L. J. Phys. Chem. 1986, 90, 2555.

(3) Nedeljkoviĉ, J. M.; Nenadovič, M. T.; Miçic̄, O. I.; Nozik, A. J. J. Phys. Chem. 1986, 90, 12.

(4) Nozik, A. J.: Williams, F.; Nenadovič, M. T.; Rahj, T.; Miçič, O. I. J. Phys. Chem. 1985, 89, 397 .

(5) Henglein, A. Ber. Bunsenges. Phys. Chem. 1984, 88, 969.

(6) Ramsden, J. J.; Webber, S. E.; Grätzel, M. J. Phys. Chem. 1985, 89, 2740 .

(7) Dannhauser, T.; O'Neil, M.; Johansson, K.; Whitten, D.; McLendon, G. J. Phys. Chem. 1986, 90,6074 .

(8) Tricot, Y.-M.; Fendler, J. H. J. Phys. Chem. 1986, 90, 3369.

(9) Variano, B. F.; Hwang, D. M.; Sandroff, C. J.; Wiltzius, P.; Jing, T. W.; Ong, N. P. J. Phys. Chem. 1987, 91, 6455.

(10) Ekimov, A. I.; Efros, AI. L.; Onushchenko, A. A. Solid State Commun. 1985, 921 .

(11) Wang. Y.; Mahler, W. Opt. Commun. 1987, 61, 233.

(12) Chestnoy, N.; Hull, R. Brus, L. E. J. Chem. Phys. 1986, 85, 2237

(13) Parise, J. B.; MacDougall, J. E.; Herron, N,; Farlee, R.; Sleight, A. W.; Wang, Y.; Bein, T.; Moller, K.; Moroney, L. M. Inorg. Chem. 1988, 27 , 221.

(14) Herron, N.; Wang, Y.; Eddy, M. M.; Stucky, G. D.; Moller, K.; Bein, T.; Cox, D. E. J. Am. Chem. Soc. 1989, $111,530$.

(15) Moller, K.; Koningsberger, D. C.; Bein, T. J. Phys. Chem., submitted.

(16) Bard, A. J. J. Phys. Chem. 1982, 86, 172.

(17) Grätzel, M. Acc. Chem. Res. 1982, 15, 376.

(18) Darwent, J. R. J. Chem. Soc., Faraday Trans. I 1984, 80, 183. 


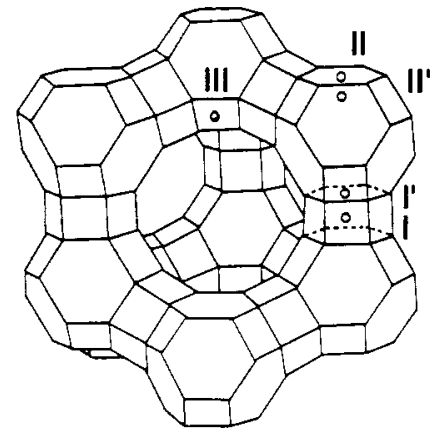

Figure 1. Cavity structure and cation positions of a partial unit cell of faujasite. Oxygen atoms of the framework are omitted.

of zeolite $\mathrm{Y}$. The sodalite unit contains four $\mathrm{SI}^{\prime}$ and four $\mathrm{SII}^{\prime}$ coordination sites, with three framework oxygens serving as ligands with $C_{3 v}$ symmetry. Very small charged species such as $\mathrm{Na}_{4}{ }^{3+19}$ or $\mathrm{Ag}_{3}{ }^{2+20}$ as well as palladium $(0)$ moieties containing only two to four atoms ${ }^{21}$ have previously been encapsulated in the cavity system of zeolite $Y$.

In this paper we illustrate the complementarity of powder X-ray diffraction (XRD) and X-ray absorption spectroscopy (EXAFS). Both techniques have been applied to the elucidation of the structure of CdSe loaded into zeolite $Y$. Synchroton radiation has opened up exciting new possibilities in all aspects of powder diffraction. The high peak to background ratio and excellent resolution enable a well-resolved pattern to be collected in about $12 \mathrm{~h}$. The simple peak shape and high resolution allow deconvolution of the powder pattern for structure determinations ${ }^{22}$ or application of the profile method devised by Rietveld. ${ }^{23}$ Consequently, the past 2 years has seen a rapid increase in the number of problems being tackled by this technique. ${ }^{24}$ Several molecular sieves have recently been investigated by high-resolution synchrotron X-ray diffraction. ${ }^{25}$ The technique is particularly useful for the determination of ion siting in zeolites where the framework structure is already known.

EXAFS recently emerged as a technique to determine number and types of neighboring atoms, interatomic distances, and mean square deviations of neighboring atom positions about equilibrium values. It is possible to obtain this information selectively for different types of the constituent atoms in the material. ${ }^{26,27}$ Since the structural information derived from EXAFS data does not rely on long-range order in the sample, EXAFS studies have played an important role in structural studies of noncrystalline systems such as heterogeneous catalysts ${ }^{28}$ and biologic materials. ${ }^{29}$ A zeolite host-guest system may represent a long-range/shortrange order composite, whose short-range order part of the guest species eludes structural determination with diffraction methods.

(19) (a) Harrison, M. R.; Edwards, P. P.; Klinowski, J.; Thomas, J. M.; Johnson, D. C.; Page, C. J. J. Solid State Chem. 1984, 54, 330. (b) Martens, L. R. M.; Grobet, P. J.; Jacobs, P. A. Nature 1985, 315, 568.

(20) (a) Gellens, L. R.; Mortier, W. J.; Schoonheydt, R. A.; Uytterhoeven, J. B. J. Phys. Chem. 1981, 85, 2783. (b) Gellens, L. R.; Mortier, W. J.; Uytterhoeven, J. B. Zeolites 1981, $l, 11$.

(21) Moller, K.; Bein, T. Proceedings of the 8th International Zeolite Conference, Amsterdam, The Netherlands, 1989 , in press.

(22) (a) Attfield, J. P.; Sleight, A. W.; Cheetham, A. K. Nature 1986, 322 , 620. (b) Lehmann, M. S.; Christensen, A. N.; Fjellvag, H.; Feidenhans'l, R.; Nielsen, M. J. Appl. Crystallogr. 1987, 20,6122.

(23) Rietveld, H. M. J. Appl. Crystallogr. 1969, 2, 65.

(24) Cox, D. E. M.R.S. Bull. 1987, 12, I.

(25) (a) Toby, B.; Eddy, M. M.; Kokotailo, G. T.; Fyfe, C. A.; Cox, D. Zeolites, in press. (b) Herron, N.; Wang, Y.; Eddy, M. M.; Stucky, G. D.; Cox, D. E., submitted to J. Am. Chem. Soc

(26) Teo, B. K.; Joy, D. C., Eds. EXAFS Spectroscopy; Plenum: New York, 1981 .

(27) Koningsberger, D. C.: Prins, R., Eds. X-ray Absorption: Principles, Applications, Techniques of EXAFS, SEXAFS, and XANES; Wiley: New York, 1988

(28) Sinfelt, J. H.; Via, G. H.; Lytle, F. W. Catal. Rev.-Sci. Eng. 1984, 26,81 .

(29) Cramer, S. P.; Gillum, W. O.; Hodgson, K. O.; Mortenson, L. E.; Stiefel, E. I.; Chisnell, J. R.; Brill, W. J.; Shah, V. K. J. Am. Chem. Soc. 1978, 100,3814 .
Table I. Crystallographic Data of Reference Powders and Their Utilization in the EXAFS Analysis

\begin{tabular}{|c|c|c|c|c|c|}
\hline \multirow[b]{2}{*}{ ref compd } & \multicolumn{2}{|c|}{$\begin{array}{l}\text { EXAFS data } \\
\text { ranges }\end{array}$} & \multicolumn{2}{|c|}{$\begin{array}{l}\text { crystallo- } \\
\text { graphic } \\
\text { data }\end{array}$} & \multirow[b]{2}{*}{ ref } \\
\hline & $\overline{k / \AA^{-1 a}}$ & $R / \AA^{b}$ & $R / \AA$ & $\bar{N}$ & \\
\hline $\begin{array}{l}\mathrm{PdO} \text { used for } \\
\text { (a) } \mathrm{Cd}-\mathrm{O} \\
\text { (b) } \mathrm{Cd}-\mathrm{Cd}\end{array}$ & $\begin{array}{l}3.1-13.4 \\
3.1-17.5\end{array}$ & $\begin{array}{l}1.2-2.2 \\
2.4-2.9\end{array}$ & $\begin{array}{l}2.017 \\
3.01\end{array}$ & $\begin{array}{l}4 \\
4\end{array}$ & $c$ \\
\hline $\begin{array}{l}\mathrm{CdSe} \text { used for } \\
\text { (a) Cd-Se, Cd edge } \\
\text { (b) Se-Cd, Se edge }\end{array}$ & $\begin{array}{l}2.5-13.3 \\
2.5-15.9\end{array}$ & $\begin{array}{l}1.9-2.8 \\
1.6-3.0\end{array}$ & 2.62 & 4 & $d$ \\
\hline $\begin{array}{l}\text { CdS used for } \\
\text { Cd-Si } \\
\text { Se powder for } \\
\text { Se-Se }\end{array}$ & $2.9-13.1$ & $1.0-3.4$ & 2.52 & 4 & $e$ \\
\hline
\end{tabular}

${ }^{a} k$ is the electron wave vector. ${ }^{b}$ Not corrected for phase shift. ${ }^{c}$ Waser, J.; Levy, H. A.; Peterson, S. W. Acta Crystallogr. 1953, 6, 661. 'Comprehensive Inorganic Chemistry; Pergamon: New York, 1973; Vol. 3. 'Wyckoff, R. W. G. Crystal Structures, 2nd ed.; Interscience: New York, 1963. fCherin, P.; Unger, P. Inorg. Chem. 1967, 6,1589 .

We have used this technique extensively as a local structural probe for the ligand environment of metal ions in zeolites, ${ }^{30}$ formation of semiconductor clusters in zeolites, ${ }^{13}$ ligand substitution and redox reactions of zeolite-adsorbed $\mathrm{Ni}(\mathrm{CO})_{4},{ }^{31}$ and intrazeolite surface reactions of iron cyclopentadienyl carbonyl species. ${ }^{32}$

EXAFS allows one to differentiate the coordination environment of different elements located at crystallographically equivalent coordination sites. In combination, Rietveld refinement of powder diffraction data determines the statistical occupancy of the atoms in crystallographically defined positions, while EXAFS yields crucial information on bond formation by monitoring the local environment of the absorber atoms.

\section{Experimental Section}

The $\mathrm{Cd}$ samples were prepared by a standard ion-exchange procedure. The starting material was commercial zeolite LZY-52. $\mathrm{NaY}(10 \mathrm{~g})$ was slurried into $1000 \mathrm{~mL}$ of distilled water. The $\mathrm{pH}$ was adjusted to 5 , and an appropriate amount of cadmium nitrate to yield stoichiometries as listed below was added. The slurry was stirred overnight at room temperature, filtered, and washed. Drying was completed by heating the sample to $673 \mathrm{~K}$ in flowing oxygen followed by brief evacuation as the sample cooled to room temperature. Hydrogen selenide gas was passed over the dried zeolites for $1 \mathrm{~h}$. The color of the sample changed from white to orange-yellow. A final evacuation was accomplished at $323 \mathrm{~K}$ before storage under an inert atmosphere in a glovebox. Chemical analysis (Galbraith Laboratories) revealed the following composition of the unit cell: CDY, Cd(18.3) Na(19.4)Al(56)Si(136); CDSE1, Cd(17.2) $\mathrm{Se}(11.4) \mathrm{Na}(21.6) \mathrm{Al}(56) \mathrm{Si}(136)$; CDSE2, Cd(5.9)Se(4.8) Na(44.2) Al(56)Si(136). Extended X-ray absorption fine-structure (EXAFS) analysis was carried out on all three samples, and $\mathrm{X}$-ray diffraction (XRD) was carried out on sample CDSE1.

X-ray Absorption Spectroscopy. EXAFS experiments were carried out at the X-11A beam line at the Brookhaven National Synchrotron Light Source with a stored electron energy of $2.5 \mathrm{GeV}$ and ring currents between 40 and $130 \mathrm{~mA}$. Data of the Cd K-edge $(26711 \mathrm{eV})$ and Se $\mathrm{K}$-edge $(12657.8 \mathrm{eV})$ were collected in transmission using a $\mathrm{Si}(400)$ crystal monochromator. The ionization chambers were filled with $\operatorname{Ar}\left(\mathrm{I}_{0}\right)$ and $\mathrm{Kr}(\mathrm{I})$.

The CdSe-loaded zeolite samples are moisture sensitive and consequently were sealed in a 1:1 dodecane/octadecane mixture under an inert atmosphere. They were kept under nitrogen until the EXAFS measurements were carried out. This procedure was found reliable for excluding air contamination. ${ }^{31}$ Data collection was done at liquid nitrogen temperature, scanning up to $1500 \mathrm{eV}$ above the absorption edge. At least two scans per sample $(20 \mathrm{~min})$ were taken.

The sample thickness was calculated to give an absorption step between 0.7 and 1 and a total absorption of $<2$. The data were analyzed with the EXAFS program developed at the University of Washington

(30) Woolery, G.; Kuehl, G.; Chester, A.; Bein, T.; Stucky, G. D.; Sayers, D. J. Phys. 1986, 47, C8, 281.

(31) Bein, T.; McLain, S. J.; Corbin, D. R.; Farlee, R. D.; Moller, K.; Stucky, G. D.; Woolery, G.; Sayers, D. J. Am. Chem. Soc. 1988, 110, 1801 (32) Moller, K.; Borvornwattananont, A.; Bein, T. J. Phys. Chem., in press. 
following published procedures. ${ }^{33}$ Background removal was accomplished by using a cubic spline function. The resulting EXAFS modulations were weighted by $k^{3}$ ( $k$, electron wave vector) and then Fourier transformed (FT) over a $k$ range of 2-12 $\left(\AA^{-1}\right)$. Data of reference and unknown were treated identically to avoid artifacts. The inner potential $E_{0}$ did not exceed the range +3 to $-3 \mathrm{eV}$.

Powders of CdS, CdSe, Se metal (all amorphous), and PdO were used as reference materials. EXAFS reference parameters were extracted as follows: the first neighbor shell of PdO was used (a) as reference for a $\mathrm{Cd}-\mathrm{O}$ coordination sphere in the unknown sample and $(b)$ the second coordination sphere $\mathrm{Pd}-\mathrm{O}-\mathrm{Pd}$ in $\mathrm{PdO}$ served as reference for a secondshell $\mathrm{Cd}-\mathrm{O}-\mathrm{Cd}$ contribution. Phase transferability can be assumed for case (a) since the phase functions of $\mathrm{Pd}$ and $\mathrm{Cd}$ are very similar, smooth functions. Amplitude transferability in case (b) is limited due to oscillating backscattering amplitude functions of $\mathrm{Pd}$ and $\mathrm{Cd}$ with slightly shifted maxima and minima. However, with the uncertainties of the structural data $(\Delta N= \pm 30 \%, \Delta R= \pm 0.02 \AA),{ }^{34}$ valuable information can be extracted. CdS provided reference data for the $\mathrm{Cd}$ to $\mathrm{Si} / \mathrm{Al}$ neighbor contribution from the zeolite framework. The potential minor errors introduced by the use of the sulfur scatterer in the first shell of this compound as reference for a second-shell $\mathrm{Cd}-\mathrm{O}-\mathrm{Si}$ interaction were considered acceptable. The CdSe sample provided reference data for the selenide and cadmium scatterer since it was examined at both edges. Selenium powder served as reference for the Se-Se scattering contribution on the Se absorption edge. Crystallographic data of the reference compounds and information about Fourier transform regions as applied in the fit procedures are listed in Table I.

Geometric model calculations for cadmium arrangements in the zeolite framework have been carried out based upon crystallographic data for faujasite $\mathrm{S}^{35}$ and bond distances for the cadmium entities from our EXAFS results. Three-dimensional drawings were obtained with the CHEM3D program (CSC, Cambridge).

Powder Synchrotron X-ray Diffraction. High-resolution X-ray powder data were collected for CDSE1 on the powder diffractometer at beam line X-13A at the Brookhaven National Synchrotron Light Source. A perfect $\mathrm{Ge}(111)$ crystal scattering in the horizontal plane was used to monochromate the incident X-ray beam. The sample and $\operatorname{LiF}(400)$ analyzer crystal scatter vertically. For a full description of the diffractometer geometry at X-13A see ref 36 . The wavelength was determined to be $1.53668 \AA$ by calibration with a Si standard. The sample was packed into a flat aluminum holder sealed with thin beryllium foil to exclude moisture, and data were collected by step-scanning from $5^{\circ}$ to $73^{\circ}$ in intervals of $0.01^{\circ}$ for periods of $2-10 \mathrm{~s}$. Longer counting times are required at larger scattering angles to counteract the falloff in the form factor. The sample container was rocked $2^{\circ}$ at each data point to reduce the effects of preferred orientation. To monitor the incident beam intensity, an ion chamber filled with nitrogen was placed before the sample. The beam size was $2.5 \times 1 \mathrm{~mm}$ in the horizontal and vertical directions, respectively. The intenstiy at the sample position was $10^{10}$ photons/s for a storage ring current of $100 \mathrm{~mA}$.

The structural refinement was carried out by using standard profile refinement techniques. The initial normalization of the data was performed with programs available at Brookhaven, and for structural refinement a modification of the original Rietveld program was employed. This program incorporates the Voigt peak shape description that is essential for analysis of powder patterns collected with the two-crystal configuration at $\mathrm{X}-13 \mathrm{~A} .{ }^{37}$ The extraframework material was revealed by standard Fourier methods.

\section{Results of the EXAFS Analysis}

The experimentally observed EXAFS modulations contain information about the local environment of the intrazeolite $\mathrm{Cd}(\mathrm{II})$ ions that is complementary to our X-ray powder diffraction results. By absorption of X-rays exceeding the binding energy of a core electron, photoelectrons are ejected from the absorber atom. The photoelectrons are backscattered from neighboring atoms to the absorbing atom, thereby producing an interference pattern of the absorption coefficient. It follows that each spectrum is a superposition of contributions of different coordination shells around the $\mathrm{Cd}$ absorber. To extract information about the atoms of

(33) Lee, P. A.; Citrin, P. H.; Eisenberger, P.; Kincaid, B. M. Rev. Mod. Phys. 1981, 53,769.

(34) Lengeler, B. J. Phys. 1986, C8, 75

(35) Bauer, W. H. Am. Mineral. 1964, 49, 697.

(36) Cox, D. E.; Hastings, J. B.; Cardoso, L. P.; Finger, L. W. Mater. Sci. Forum 1986, 9, 1 . Phys.
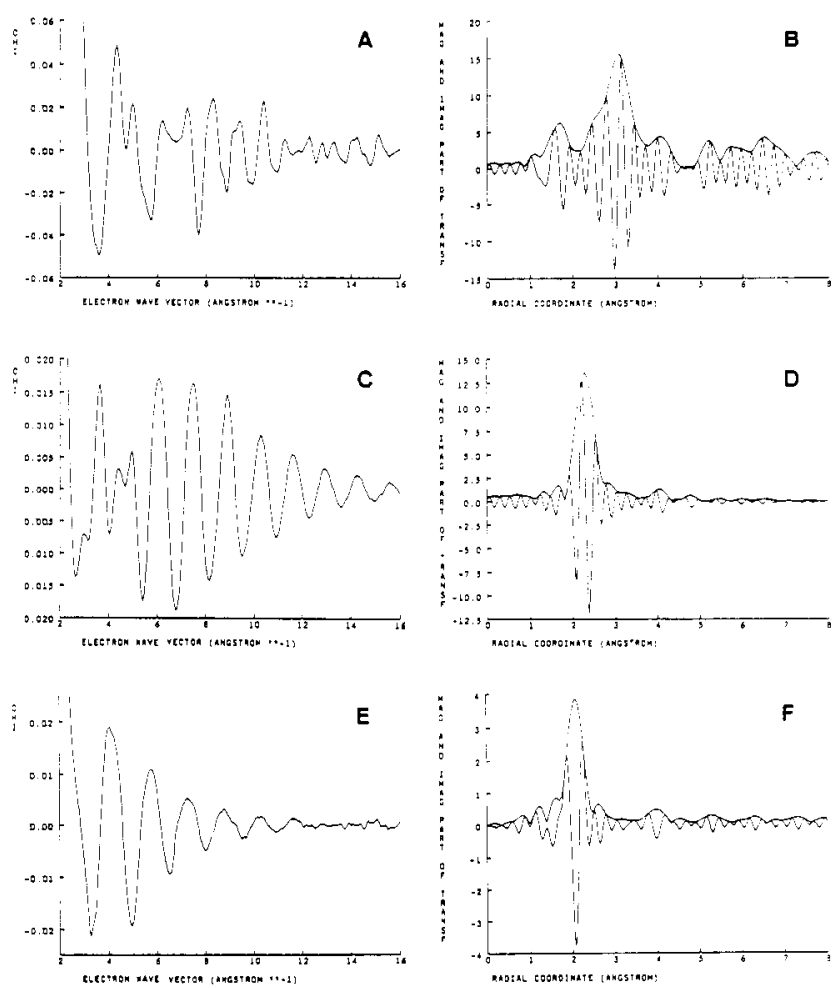

Figure 2. Normalized EXAFS data and Fourier transformations of Cd-edge EXAFS reference data: (A, B) PdO; (C, D) CdSe (amorphous); (E, F) CdS (amorphous).
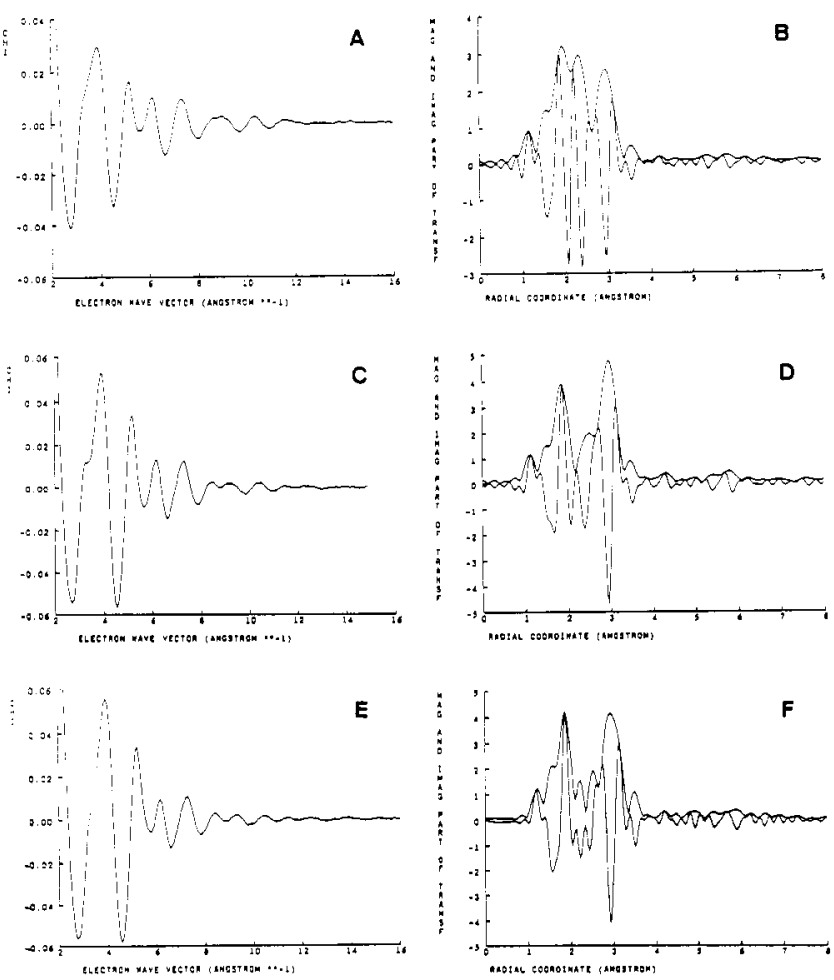

Figure 3. Cd-edge normalized EXAFS data and Fourier transformations of $(A, B)$ sample CDSE1, (C, D) sample CDSE2, and (E, F) sample CDY

interest, subtraction of the background absorption and normalization have to be performed. A Fourier transformation from energy into the radial coordinate space ( $R$ space) allows for a separation of different shells. All peaks are shifted to lower $\mathbf{R}$ values due to phase-shift effects. Figures 2 and 3 show EXAFS modulations of the original data after background removal and normalization as well as Fourier transformations of reference and 
Table II

\begin{tabular}{|c|c|c|c|c|c|}
\hline $\begin{array}{l}\text { scatterer } \\
\text { pair }\end{array}$ & assignment & $\begin{array}{c}\text { bond dist } \\
R / \AA\end{array}$ & $\begin{array}{c}\text { coord no. } \\
N\end{array}$ & $\begin{array}{c}\text { Debye-Waller } \\
\Delta \delta^{2} / \AA^{2}\end{array}$ & $\begin{array}{c}\text { model } \\
N^{a}\end{array}$ \\
\hline \multicolumn{6}{|c|}{ CDSE 1} \\
\hline \multicolumn{6}{|l|}{ Cd edge } \\
\hline $\mathrm{Cd}-\mathrm{O}$ & $\mathrm{Cd}-\mathrm{OZ}\left(\mathrm{SI}^{\prime}\right)$ & 2.39 & 2.2 & -0.001 & 2.1 \\
\hline $\mathrm{Cd}-\mathrm{O}$ & $\mathrm{Cd}-\mathrm{O}(5)$ & 2.26 & 1.4 & 0.003 & 1.4 \\
\hline $\mathrm{Cd}-\mathrm{O}$ & $\mathrm{Cd}-\mathrm{OZ}(\mathrm{SIII} / \mathrm{O}(6))$ & 2.58 & 1.2 & 0.0014 & 1.2 \\
\hline $\mathrm{Cd}-\mathrm{Se}$ & $\mathrm{Cd}-\mathrm{Se}\left(\mathrm{SII}^{\prime} /\right.$ s.c. $)$ & 2.62 & 1.3 & 0.0023 & 0.65 \\
\hline $\mathrm{Cd}-\mathrm{Si} / \mathrm{Al}$ & & 3.40 & 6.3 & 0.0019 & 5.4 \\
\hline $\mathrm{Cd}-\mathrm{Cd}$ & $\mathrm{Cd}-\mathrm{Cd}\left(\mathrm{SI}^{\prime}\right)$ & 3.26 & 0.4 & -0.0003 & 0.7 \\
\hline \multicolumn{6}{|l|}{ Se edge } \\
\hline $\mathrm{Se}-\mathrm{Cd}$ & $\mathrm{Se}-\mathrm{Cd}\left(\mathrm{SI}^{\prime} / \mathrm{SIII}\right)$ & 2.60 & 2.1 & 0.0013 & 1.0 \\
\hline \multirow[t]{2}{*}{$\mathrm{Se}-\mathrm{Se}$} & Se-Se chains & 2.39 & 0.7 & 0.0000 & \\
\hline & \multicolumn{5}{|c|}{ CDSE2 } \\
\hline \multicolumn{6}{|l|}{$\mathrm{Cd}$ edge } \\
\hline $\mathrm{Cd}-\mathrm{O}$ & $\mathrm{Cd}-\mathrm{OZ}\left(\mathrm{SI}^{\prime}\right)$ & 2.42 & 2.6 & 0.00024 & 2.25 \\
\hline $\mathrm{Cd}-\mathrm{O}$ & $\mathrm{Cd}-\mathrm{O}(5) /$ cube & 2.27 & 2.2 & -0.0015 & 2.25 \\
\hline $\mathrm{Cd}-\mathrm{Se}$ & CdSe cluster & 2.61 & 1.0 & 0.007 & \\
\hline $\mathrm{Cd}-\mathrm{Si} / \mathrm{Al}$ & & 3.38 & 6.3 & -0.0016 & 5.4 \\
\hline $\mathrm{Cd}-\mathrm{Cd}$ & $\mathrm{Cd}-\mathrm{Cd}\left(\mathrm{SI}^{\prime}\right) /$ cube & 3.36 & 2.6 & 0.007 & 2.25 \\
\hline \multicolumn{6}{|l|}{ Se edge } \\
\hline $\mathrm{Se}-\mathrm{Cd}$ & CdSe cluster & 2.60 & 0.9 & 0.0014 & \\
\hline $\mathrm{Se}-\mathrm{Se}$ & Se-Se (chains) & 2.37 & 2.0 & 0.0006 & \\
\hline
\end{tabular}

${ }^{a}$ Theoretical coordination numbers for $\mathrm{Cd}^{2+}$ in (a) sample CDSE1 with $70 \% \mathrm{Cd}$ located at $\mathrm{SI}^{\prime}$ sites and $30 \%$ SIII forming ensembles as described in the text and (b) sample CDSE2 with $75 \% \mathrm{Cd}$ located at SI' forming $\mathrm{Cd}_{4} \mathrm{O}_{4}$ clusters. $\mathrm{CdSe}$ and Se helical chains are not included in the calculation of coordination numbers. Estimated errors: $N, \pm 20 \% ; R, \pm 0.02 \AA ; \Delta \delta^{2}, \pm 20 \%$ for the Cd edge; $N, \pm 10 \% ; R, \pm 0.01 \AA, \Delta \delta^{2}, \pm 10 \%$ for the Se edge.

unknown samples taken on the $\mathrm{Cd}$ absorption edge, while Figure 8 and 9 show EXAFS modulations for those of the corresponding Se absorption edge.

Sample CDSE1. A comparison between the cadmium-exchanged zeolite CdY (Figure 3E,F) and the samples treated with hydrogen selenide gas shows that major changes occur in sample CDSEl (Figure 3A,B). Thus we will begin the analysis by examining this sample first. The Fourier transformation (Figure 3B) shows three overlapping backscatterer contributions. Normal Fourier filtering and curve-fitting techniques are difficult in this case, because the resulting $\chi$ functions will always be composed of more than one coordination shell. On the other and, a three-shell fit over the whole data range would involve at least nine variables to account for the bond distance $(R)$, number of neighbors $(N)$, and deviations from the Debye-Waller factors $\left(\Delta \delta^{2}\right)$ in each shell. If the potential distribution of $\mathrm{Cd}(\mathrm{II})$ over different framework positions is considered, it is clear how demanding such an analytical approach would be. We have therefore used a difference-file-technique, which has been employed successfully by Koningsberger et al, on similar complex systems. ${ }^{38}$

The "precursor" sample CDY was previously analyzed by utilizing EXAFS and is discussed in detail in a recent publication. ${ }^{14}$ It was found that four $\mathrm{Cd}^{2+}$ ions occupy $\mathrm{SI}^{\prime}$ cation positions in the sodalite cages and that they are bridged by oxygen in adjacent SII' six-ring sites, thus forming small $\mathrm{Cd}_{4} \mathrm{O}_{4}$ cubes. Sample CDSE 1 was prepared by treating a similar Cd(II) zeolite with $\mathrm{H}_{2} \mathrm{Se}$ gas at room temperature. Since the selenium reacts with cadmium, the sample is expected to differ from the $\mathrm{Cd}(\mathrm{II})$ zeolite in its overall appearance primarily by an additional selenium shell. If the FT spectra of both samples (Figure 3B,F) are compared, a new peak at $\sim 2.3 \AA$ (uncorrected) in CDSE1 appears due to the selenide in this system. This assignment is further justified by the striking similarity in phase function and location in $R$ space to that of the reference sample CdSe (Figure 2D). The first and third peaks of CDSEl result primarily from the oxygen and $\mathrm{Si} / \mathrm{Al}$ scatterer of the zeolite framework. Subtraction of the selenide component from the original file separates the two remaining shells and allows fitting of single shells. For the calculation of the $\mathrm{Cd}-\mathrm{Se}$ scatterer pair, the unknown parameters for the selenide neighbors were derived from $\mathrm{CdSe}$ and adjusted until a difference file resulted that was similar to the Se-free CDY sample. The resulting difference file is shown in Figure 4A. The separation into two

(38) van't Blik, H. F. J.; van Zon, J. B. A. D.; Huizinga, T.; Vis, J. C.; Koningsberger, D. C.; Prins, R. J. Am. Chem. Soc. 1985, I07, 3139
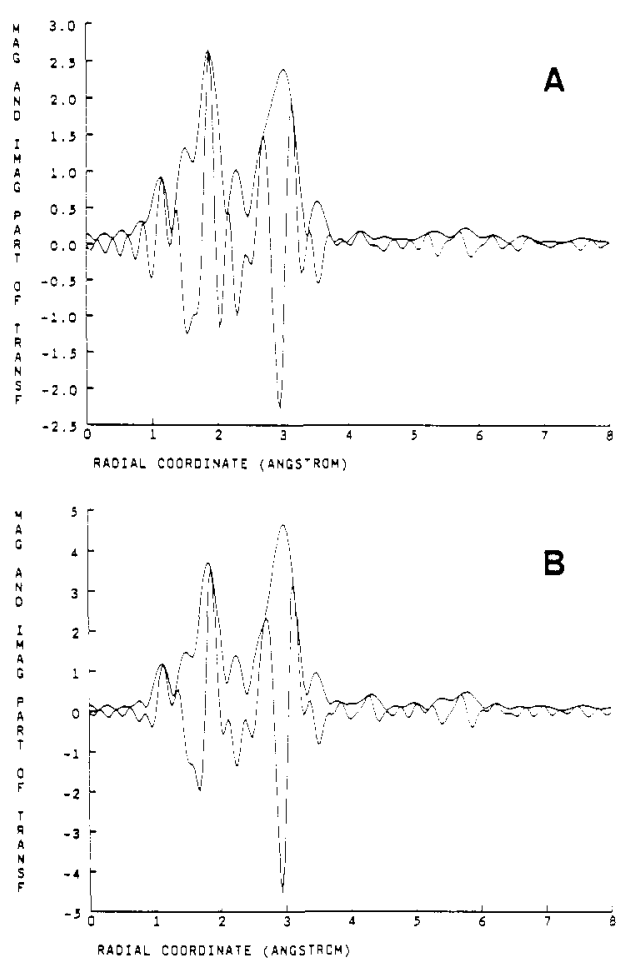

Figure 4. (A) $k^{3}$ Fourier transformation of the difference file of CDSE1 minus a calculated contribution for $\mathrm{CdSe}\left(\mathbf{R}=2.62, N=1, \Delta \delta^{2}=\right.$ 0.001 ). (B) $k^{3}$ Fourier transformation of the difference file of CDSE2 minus a calculated contribution for $\operatorname{CdSe}\left(R=2.62 \AA, N=0.8, \Delta \delta^{2}=\right.$ $0.0023)$.

shells is now visible, but a remnant remains at $\sim 2.2 \AA$.

Assuming only minor overlap of this residue with the first major peak, a backtransformation was applied to this difference file, using a narrow window of $1.3-2.1 \AA$. A fit was only possible with two different oxygen scatterer distances at 2.26 and $2.39 \AA$ (Figure $5 \mathrm{~A}$; final fit results are listed in Table II). A broader window of $1.3-2.4 \AA$ including the remnant was subsequently used with an additional $\mathrm{Cd}-\mathrm{O}$ shell, applying the previously obtained values. As can be seen in Figure 5B, the $\chi$ function now has a different envelope due to the small amount of the additional scatterer present. In a third step, a backtransformation on the shell at $\sim 3$ $\AA$ in the difference file was applied between 2.4 and $3.3 \AA$. A 

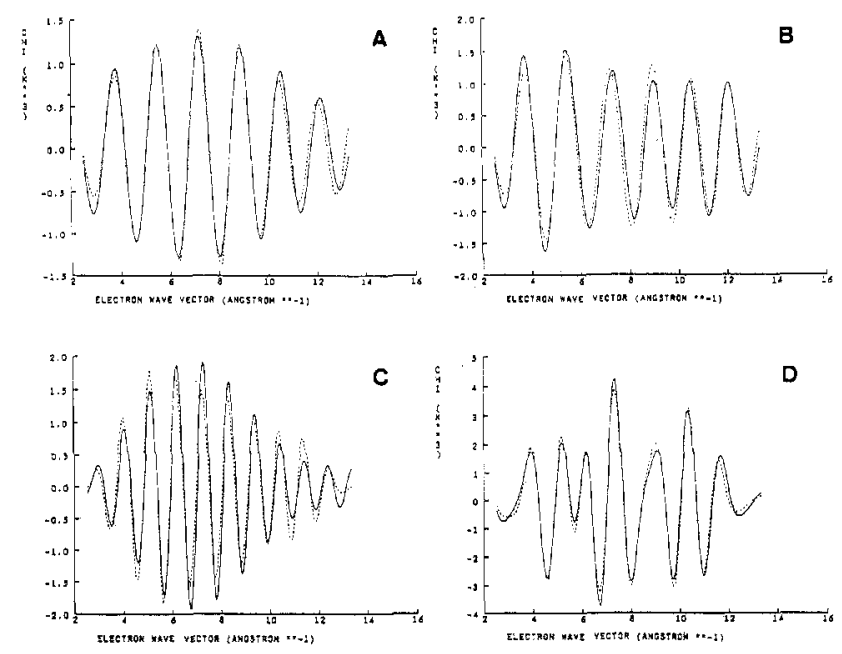

Figure 5. $k^{3}$ normalized EXAFS data and calculated EXAFS of the difference file of CDSEl (data, solid line; final fit, broken line): (A) 1.3-2.1 $\AA, \mathrm{Cd}-\mathrm{O}$ contribution; (B) 1.3-2.4 $\AA, \mathrm{Cd}-\mathrm{O}$ with additional $\mathrm{Cd}-\mathrm{O}$ of $2.58 \AA$; (C) 2.4-3.3 $\AA, \mathrm{Cd}-\mathrm{Si} / \mathrm{Al}$ contribution; (D) 1.3-3.3 $\AA$, original CDSE1 file (solid line), final fit (broken line).
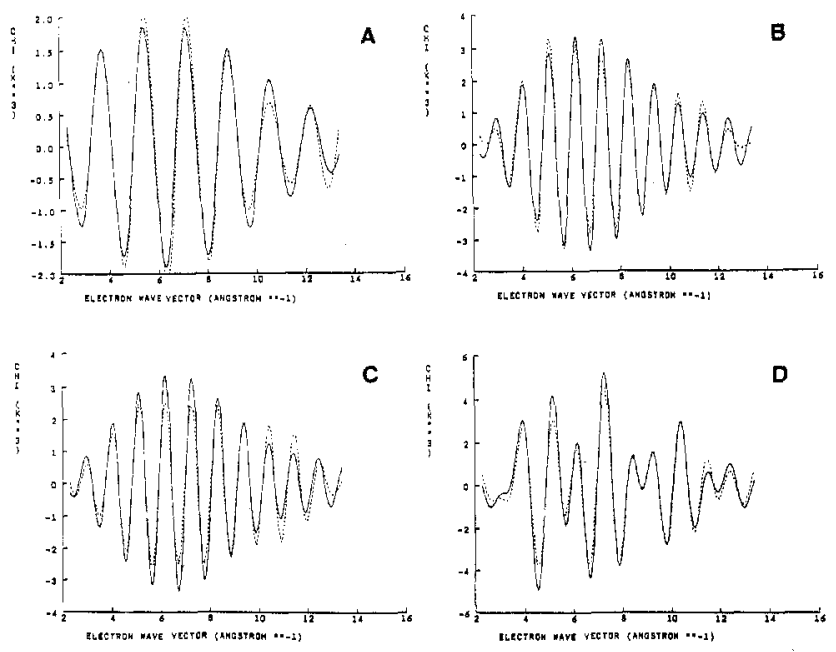

Figure 6. $k^{3}$ normalized EXAFS data and calculated EXAFS of the difference file of CDSE2: (A) 1.5-2.1 $\AA, \mathrm{Cd}-\mathrm{O}$ contribution; (B) 2.4-3.3 $\AA, \mathrm{Cd}-\mathrm{Si} / \mathrm{Al}$ contribution; (C) 2.4-3.3 $\AA, \mathrm{Cd}-\mathrm{Si} / \mathrm{Al}$ with additional Cd-Cd contribution; (D) 1.5-3.3 $\AA$, original CDSE2 file (solid line), final fit (broken line).

fit with $\mathrm{CdS}$ as reference for the presumed $\mathrm{Cd}-\mathrm{Si} / \mathrm{Al}$ neighbors and a small amount of a $\mathrm{Cd}-\mathrm{O}-\mathrm{Cd}$ scatterer was performed (Figure 5C). Finally, all parameters, accounting in total for six different bond distances to four different types of scatterer, were used on the whole data file between 1.3 and $3.3 \AA$. Only minor adjustments on the values derived from the separate single-shell fits were necessary to obtain the result shown in Figure 5D. A very good fit is achieved considering the complexity of the sample. The results are listed in Table II. The fit shows good agreement with the original sample, as confirmed by comparison of the respective FT on the calculated file (Figure 7A). Its magnitude and imaginary part are very sensitive to incorrect assignments of scattering neighbors.

Since a cadmium-selenium pair is identified in the above analysis, it has to be present with a similar bond length when the sample is examined from the selenium edge. The raw $\chi$ data and their Fourier transformation (2.6-15.9 $\AA$ ) are shown in Figure 9A,B. The similarity of these data to the cadmium selenide reference (Figure $8 \mathrm{~A}, \mathrm{~B}$ ) is immediately apparent. They differ only by a small shoulder at $\sim 2.0 \AA$ (uncorrected) in sample CDSE1. The fits only converged satisfactorily when the second scatterer was Se. Excellent results were achieved with a singlebond distance for Se-Cd of $2.60 \AA$, very close to the $2.62 \AA$ of

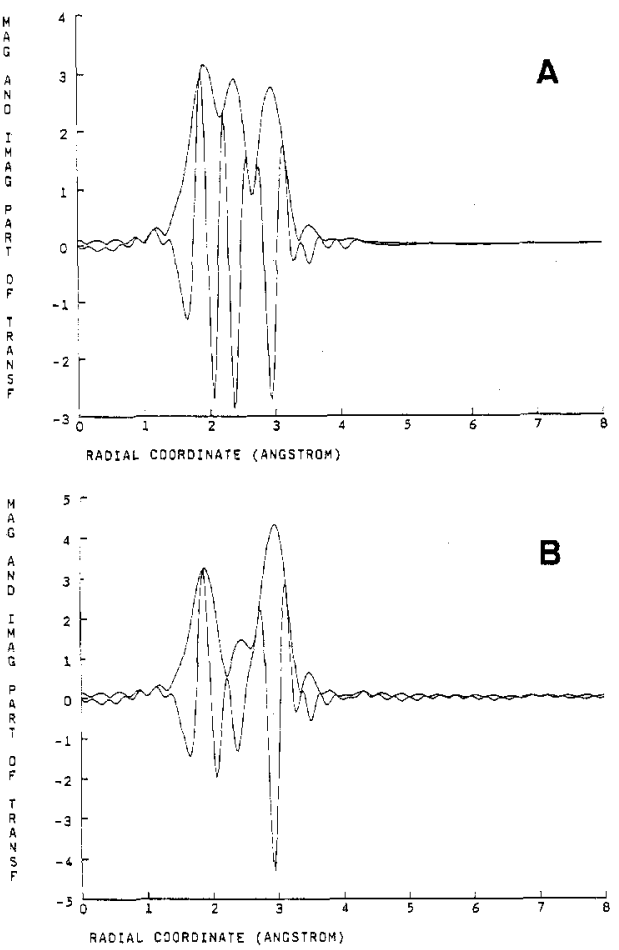

Figure 7. $k^{3}$ Fourier transformation of the calculated EXAFS of (A) CDSE1 and (B) CDSE2.
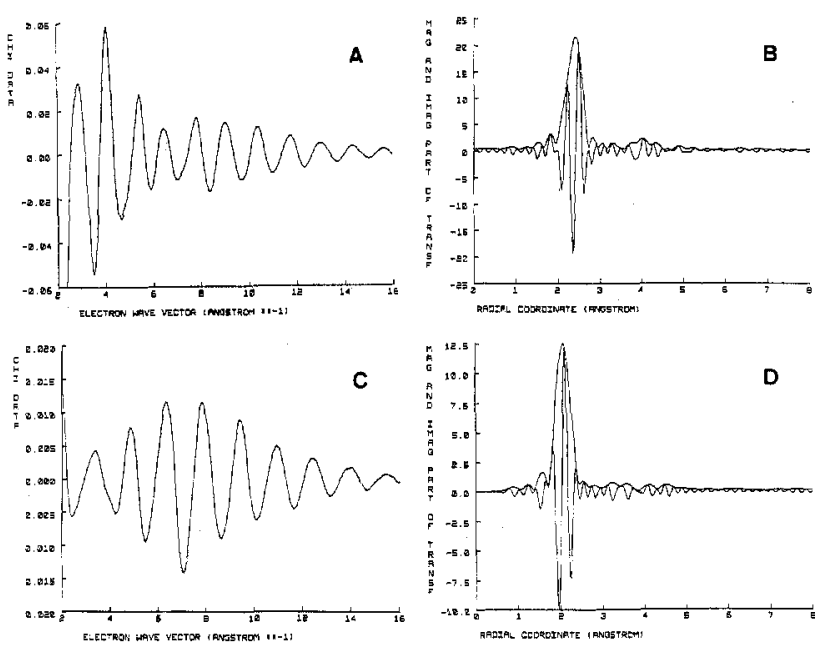

Figure 8. Normalized EXAFS data and Fourier transformations of Se-edge EXAFS reference data: (A, B) CdSe; (C, D) Se powder.

the fit described above, and additional Se-Se at $2.39 \AA$ (Figure 10A). The agreement between the independent analyses on both absorption edges makes the formation of cadmium selenide fragments unquestionable.

Sample CDSE2. Sample CDSE2 contains only $6 \mathrm{Cd}^{2+} / \mathrm{uc}$ and a higher $\mathrm{Se} / \mathrm{Cd}$ ratio (about 1:1). The Cd EXAFS data are quite different from those of CDSE1 (see FT in Figure 3D). The intensity of the peak at $\sim 3 \AA$ initially assigned to $\mathrm{Si} / \mathrm{Al}$ is much larger than that of CDSE1, while a Se contribution at $\sim 2.3 \AA$ is decreased in intensity and much broader, indicating a higher degree of disorder. An approach similar to that described above was used to solve the structure of this sample. After a calculated contribution for $\mathrm{Cd}-\mathrm{Se}$ is subtracted, the FT of the difference file (see Figure 4B) is very similar to that of CDY (Figure 3F)

A fit of the first shell of this difference file (1.3-2.1 $\AA$ ) again results in two different bond distances for oxygen at 2.27 and 2.42 $\AA$ (see Figure $6 \mathrm{a}$ ). The shell at $\sim 3 \AA$, when fitted only considering a $\mathrm{Si} / \mathrm{Al}$ contribution (Figure $6 \mathrm{~B}$ ), results in a very high number of neighbors (12.5 uncorrected), which is chemically unreasonable. It follows that there must be an additional con- 

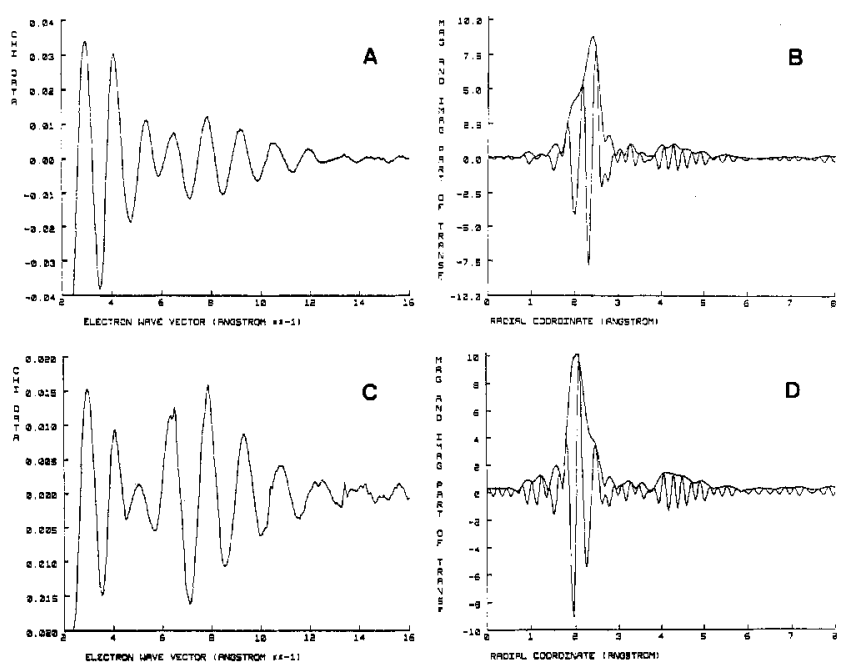

Figure 9. Se-edge normalized EXAFS data and Fourier transformations of (A, B) sample CDSE1 and (C, D) sample CDSE2.
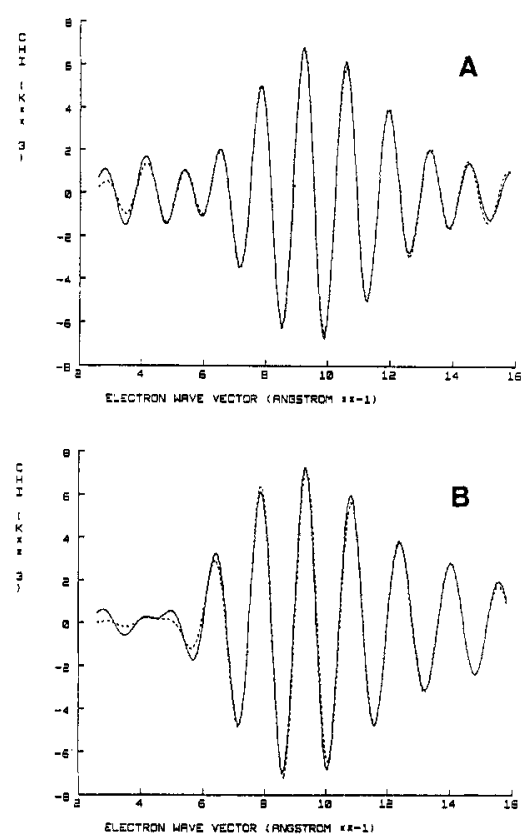

Figure 10. $k^{3}$-weighted normalized EXAFS data (solid line) and fit (broken line) of Se-edge EXAFS data: (A) sample CDSE1; (B) sample CDSE2.

tribution to this peak, similar to that found for CDY. A fit including a $\mathrm{Cd}-\mathrm{Cd}$ shell is shown in Figure $6 \mathrm{C}$. This results in $2.6 \mathrm{Cd}$ neighbors contributing to this peak and brings the number of $\mathrm{Si} / \mathrm{Al}$ atoms in the second shell down to 6.3 (uncorrected), a value expected for a cation close to a zeolite six-ring cation position. A fit over the data range between 1.3 and $3.3 \AA$ was obtained with these values and is shown in Figure $6 \mathrm{D}$. The final values are listed in Table II.

The presence of Se-Se scattering in the selenium-edge data of this sample is striking (Figure 9C,D). In CDSE2, the average Se-Se contribution at $2.37 \AA$ amounts to 2 neighbors as compared with only 0.7 neighbors in sample CDSE1. In contrast, in sample CDSE1 the Se-Cd contribution at $2.60 \AA(2.1 \mathrm{Cd} / \mathrm{Se})$ is higher than that in CDSE2 $(0.9 \mathrm{Cd} / \mathrm{Se}$ ) (see Figure 10B). The excellent agreement of $\mathrm{Cd}-\mathrm{Se}$ bond distances obtained from $\mathrm{Cd}-$ and Seedge data illustrates the reliability of the structural data obtained.

\section{Results of Powder Synchrotron X-ray Diffraction}

The observed, calculated, and difference profiles for sample CDSE1 are illustrated in Figure 11. The refined atomic and profile parameters are given in Table III with selected bond lengths in Table IV. An excellent refinement was obtained, which is

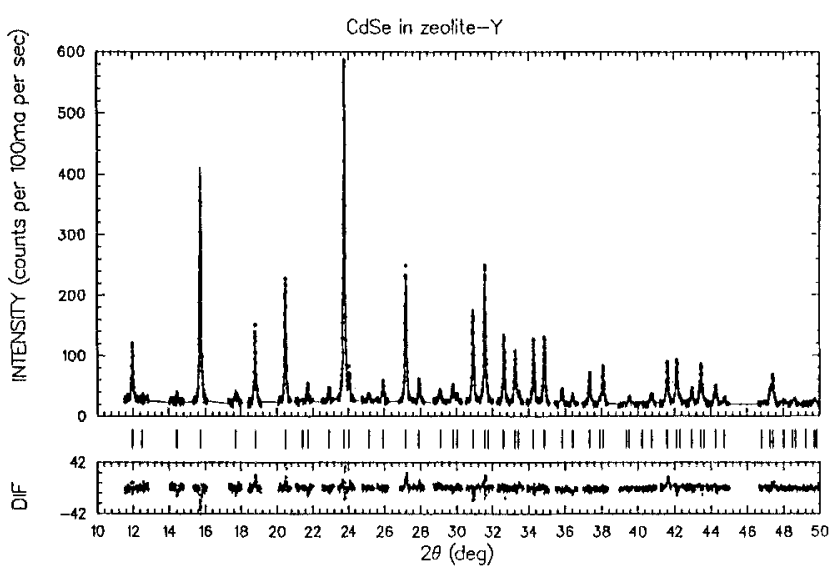

Figure 11. Observed (dots) and calculated (solid line) X-ray powder diffractogram profiles of sample CDSE 1 and their difference.

Table III. Refined Atomic and Structural Parameters for Sample CDSE1 (Space Group Fd3m (International Tables I No. 227); Origin at Center $)^{a}$

\begin{tabular}{lccccc}
\hline \multicolumn{7}{c}{ Atomic Parameters } \\
\hline $\mathrm{T}(1)$ & $-0.0532(1)$ & $0.1250(1)$ & 0.0365 & \multicolumn{1}{c}{$\boldsymbol{B} / \AA^{2}$} & occupancy \\
$\mathrm{O}(1)$ & 0.0 & $-0.1047(2)$ & $0.1047(2)$ & $2.3(2)$ & 192 \\
$\mathrm{O}(2)$ & $-0.0067(3)$ & $-0.0067(3)$ & $0.1423(4)$ & $2.5(2)$ & 96 \\
$\mathrm{O}(3)$ & $0.0730(2)$ & $0.0730(2)$ & $-0.0284(4)$ & $1.7(2)$ & 96 \\
$\mathrm{O}(4)$ & $0.0742(2)$ & $0.0742(2)$ & $0.3213(3)$ & $0.8(2)$ & 96 \\
$\mathrm{Na}(1)$ & $0.2391(4)$ & $0.2391(4)$ & $0.2391(4)$ & $0.8(2)$ & $15.8(4)$ \\
$\mathrm{Cd}(1)$ & $0.0693(1)$ & $0.0693(1)$ & $0.0693(1)$ & $0.8(2)$ & $11.4(1)$ \\
$\mathrm{Cd}(2)$ & $0.42(1)$ & $0.212(1)$ & $0.183(1)$ & $0.8(2)$ & $5.2(2)$ \\
$\mathrm{O}(5)$ & $0.1646(4)$ & $0.1646(4)$ & $0.1646(4)$ & $0.8(2)$ & $28.9(6)$ \\
$\mathrm{O}(6)$ & $0.132(2)$ & $0.465(2)$ & $0.1646(2)$ & $0.8(2)$ & $17.8(9)$ \\
$\mathrm{Se}(1)$ & $0.093(2)$ & $0.018(2)$ & $0.478(2)$ & $0.8(2)$ & $5.0(3)$
\end{tabular}

\begin{tabular}{lccccc}
\multicolumn{5}{c}{ Profile Parameters } \\
zeropt & $1.76(5)$ & $Y$ & $4.5(1)$ & $R_{\mathrm{e}}$ & $18.2 \%$ \\
$U$ & $406(31)$ & $R_{\mathrm{n}}$ & $10.2 \%$ & $X^{2}$ & 1.4 \\
$V$ & $-64(25)$ & $R_{\mathrm{pr}}$ & $21.0 \%$ & & \\
$W$ & $52(5)$ & $R_{\mathrm{wpr}}$ & $21.6 \%$ & & \\
$X$ & 0 & & & & \\
\hline${ }^{a} a=b=c=24.6366(7) \AA$.
\end{tabular}

Table IV. Selected Bond Distances $(\AA)$ for Sample CDSE1

\begin{tabular}{llll}
\hline framework & \multicolumn{3}{c}{ extraframework } \\
\hline $\mathrm{T}(1)-\mathrm{O}(1)$ & $1.63(1)$ & $\mathrm{Na}(1)-3 \times \mathrm{xO}(2)$ & $2.42(1)$ \\
$\mathrm{T}(1)-\mathrm{O}(2)$ & $1.64(1)$ & $\mathrm{Cd}(1)-2 \mathrm{xO}(3)$ & $2.41(1)$ \\
$\mathrm{T}(1)-\mathrm{O}(3)$ & $1.68(1)$ & $\mathrm{Cd}(1)-3 \mathrm{xO}(5)$ & $2.42^{a}$ \\
$\mathrm{~T}(1)-\mathrm{O}(4)$ & $1.62(1)$ & $\mathrm{Cd}(2)-\mathrm{O}(1)$ & $2.74(2)^{b}$ \\
mean & 1.643 & $\mathrm{Cd}(2)-\mathrm{O}(4)$ & $2.70(2)^{b}$ \\
expected & 1.639 & $\mathrm{Cd}(2)-\mathrm{O}(6) / \mathrm{Se}(1)$ & $2.40(8)^{c}$ \\
& & & $2.64(8)^{c}$ \\
& & & $3.06(6)^{c}$ \\
& & & $3.25^{c}$ \\
& & & $2.25(7)^{c}$ \\
& & & $2.17^{c}$ \\
& & & $2.82^{c}$
\end{tabular}

${ }^{a}$ This value represents weighted mean distances for both $\mathrm{Cd}-\mathrm{O}(5)$ and $\mathrm{Cd}-\mathrm{Se}(1)$ present in the sodalite cages. ${ }^{b}$ Coordination to SIII. ${ }^{c}$ These sites are disordered and only partially occupied. Chemically reasonable bond distances are shown for $\mathrm{Cd}-\mathrm{O}(6)$ or $\mathrm{Cd}-\mathrm{Se}(1)$ at SIII positions.

reflected in the small value of $X^{2}$.

The refined structure shows a zeolite framework that is essentially unchanged from the parent sodium zeolite $\mathrm{Y}$. The average T-O bond length $(1.64 \AA)$ is in good agreement with that expected for a zeolite of this $\mathrm{Si} / \mathrm{Al}$ ratio (2.61). Space group $F d 3 m$ (origin at center) was used throughout the refinement, which assumes a random distribution of silicon and aluminum in the tetrahedral position, and a suitable scattering length was calculated based on the $\mathrm{Si} / \mathrm{Al}$ ratio. The powder peak shape could be accurately described by the convolution of Gaussian and Lorentz 
functions - the Voigt function. No asymmetry could be detected in the low-angle reflections.

While the overall framework is as expected, there are small variations in the individual $\mathrm{T}-\mathrm{O}$ bond lengths. These are rationalized in terms of the approach of the cations to the framework oxygen. The sodium cations are located at SII, trigonally coordinated to three framework oxygen atoms. This has been found to be the most energetically favorable site for sodium. ${ }^{39}$ The $\mathrm{Cd}^{2+}$ is located primarily at $\mathrm{SI}^{\prime}$. This site, within the sodalite unit, is preferred by multivalent cations because some of the high charge density can be compensated by hydroxyl anions at SII' also in the sodalite unit. The cadmium at $\mathrm{SI}^{\prime}$ has a pseudooctahedral coordination resulting from trigonal coordination to framework oxygens of the six-ring (which is part of the double six-ring interconnects of the zeolite $\mathrm{Y}$ structure) with a bond length of $\mathrm{Cd}(1)-\mathrm{O}(3)=2.41 \AA$, and the three $\mathrm{SII}^{\prime}$ atoms, $\mathrm{Cd}(1)-\mathrm{O}(5)=$ $2.42 \AA$. $\mathrm{O}(5)$ represents a site jointly occupied by Se and oxygen, and hence the $\mathrm{Cd}(1)-\mathrm{O}(5)$ bond length is a weighted average of $\mathrm{Cd}-\mathrm{O}$ and $\mathrm{Cd}-\mathrm{Se}$. Remaining electron density, detected in the difference Fourier synthesis, was found in the twelve-ring window and assigned to $\mathrm{Cd}(2)$. This site, SIII, is bound to two framework oxygen atoms at 2.70 and $2.74 \AA$ and nonframework atoms, designated $1 \mathrm{Se}(1)$ and 2-3 $\mathrm{O}(6)$. The many disordered sites present in this region make unequivocal assignment of the scattering density difficult, and thus the information gleaned from EXAFS is of paramount importance. The total cadmium content based on the occupancy of these two positions is 16.6, in good agreement with that found from chemical analysis (17.2).

\section{Discussion}

The evaluation of Cd- and Se-edge EXAFS data combined with $\mathrm{X}$-ray powder diffraction results offers detailed insight into the structural features of the new zeolite-stabilized CdSe phases. The high-quality fits obtained with both methods support the following interpretation: Several different phases exist in the samples. In CDSE1 the major fraction is composed of cadmium cations in adjacent $\mathrm{SI}^{\prime}$ positions bridged on average by two extraframework oxygen ions in $\mathrm{SII}^{\prime}$ sites and one additional selenium ion in $\mathrm{SII}^{\prime}$ sites. The second phase consists of $\mathrm{Cd}$ ions, present in the 12-ring windows of the large cavities (SIII) coordinated to extraframework oxygen and one selenium. In sample CDSE2, the sodalite unit does not contain Se but is composed of $\mathrm{Cd}_{4}(\mathrm{O})_{4}$ "cubes". Cd-Se bonds are formed by a small fraction of CdSe clusters, which to an even smaller amount may also be present in sample CDSE1. Furthermore, Se helical chains appear to be present, in particular in sample CDSE2. This model is based upon the following arguments.

Cadmium Positions and Coordination to Zeolite Oxygen. As extracted from the EXAFS data, the combined presence of oxygen in the first shell and $\mathrm{Si} / \mathrm{Al}$ neighbors in the second shell for both samples indicates that $\mathrm{Cd}^{2+}$ ions must be located close to the framework. This was confirmed by the Rietveld analysis, which detected $70 \%$ of the cations coordinated to three zeolite oxygens $\left(\mathrm{SI}^{\prime}\right)$ and $30 \%$ at SIII sites in sample CDSE1. The $\mathrm{Cd}-\mathrm{OZ}$ bond distance of $2.39 \AA$ derived from EXAFS data is attributed to $\mathrm{SI}^{\prime}$ ions, which is in excellent agreement with the XRD results (2.41 $\AA)$. The high occupancy in the sodalite six-rings also explains the large number of $\mathrm{Si} / \mathrm{Al}$ neighbors detected with EXAFS. In sample CDSE1, a second, longer $\mathrm{Cd}-\mathrm{O}$ bond distance was detected with both methods (EXAFS, $2.58 \AA$; XRD, $2.70 \AA$ ) and assigned to $\mathrm{Cd}-\mathrm{OZ}$ in SIII sites by XRD. Data from both methods exclude the occupancy of cadmium ions in the double six-rings (SI).

Cadmium-Cadmium Interactions. Due to the high multiplicity of equivalent sites in the zeolite structure, XRD refinements can only provide average population values. In contrast, EXAFS results yield evidence for local cluster formation in the zeolite cages. However, a mixture of different phases will also result in average values of coordination numbers. The local correlation

(39) Sanders, M. J.; Catlow, C. R. A. Proceedings of the 6th International Zeolite Conference, Reno, NV, 1983; Olson, D., Bisio, A., Eds.; Butterworths: Guildford, 1984; p 131
A

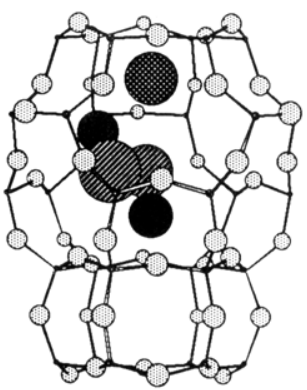

C

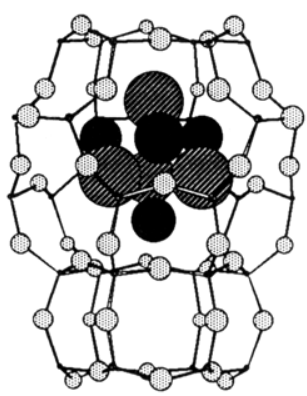

B

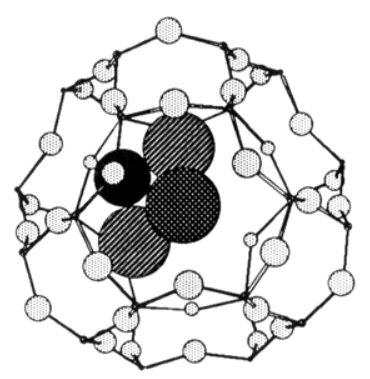

D

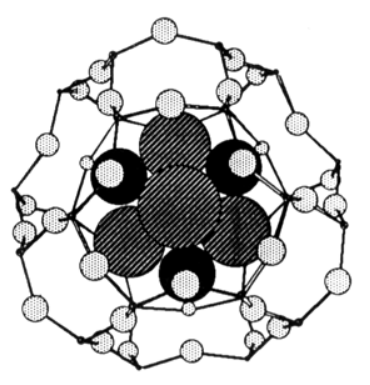

Figure 12. Geometric arrangements of cadmium selenide species in a sodalite subunit of the zeolite framework, viewed from the side and from the top. Framework oxygens, light shaded; extraframework oxygens, dark striped; Cd cations, black; Se atom, dark dotted. Radii: $R=1.32$ $\AA$ for $\mathrm{O}^{2-}, R=0.97$ for $\mathrm{Cd}^{2+}$, and $R=1.17$ for covalent Se. (A, B) $\mathrm{Cd}\left(\mathrm{O}_{2}\right) \mathrm{CdSe}$-bridged fragment; $(\mathrm{C}, \mathrm{D}) \mathrm{Cd}_{4} \mathrm{O}_{4}$ cube. One sodalite unit incorporating the $\mathrm{Cd}$ moieties and one of the four interconnecting double six rings of the faujasite framework are presented. All framework atoms are sized $25 \%$ of their radii. For clarity, the cube ensembles are shown with $75 \%$ of the radii.

derived from EXAFS is demonstrated in CDSE2, where a significant fraction of the third shell is due to $\mathrm{Cd}-\mathrm{Cd}$ interactions at $3.36 \AA$. The close contact of cadmium ions is most likely for cations occupying the same sodalite cage simultaneously. If it is assumed that all cadmium ions in $\mathrm{SI}^{\prime}$ sites $(70 \%$ of the total amount) fill all possible $4 \mathrm{SI}^{\prime}$ positions per sodalite, the local coordination would result in an average encounter of $2.1 \mathrm{Cd}$ neighbors per atom (in other words, each Cd is surrounded by three other Cd atoms: $3 \times 0.7=2.1)$. However, in sample CDSE1, this number is considerably smaller, suggesting only partial filling of these sites.

Coordination to Extraframework Species. Extraframework oxygen atoms $(\mathrm{O} 5)$, presumably from water or hydroxyl anions remaining after the degassing procedure, were found by both methods. Oxygen atoms with a Cd-O bond distance of $2.26 \AA$ resemble those previously found in sample $\mathrm{CdY}$ which were part of a $\mathrm{Cd}_{4}(\mathrm{O})_{4}$ cube arrangement in the sodalite. ${ }^{14}$

Sample CDSE1. In this sample the coordination number for $\mathrm{Cd}-\mathrm{O}$ at $2.26 \AA$ is about half of that expected for a complete cube arrangement (expected for $70 \% \mathrm{Cd}$ located in sodalite cage: $N$ $=3 \times 0.7=2.1$; found: $N=1.4$ ). In addition, the small Cd-Cd interaction $(N=0.4)$ is not sufficient to account for a complete cube arrangement. According to the XRD results, the cadmium cations are located in $\mathrm{SI}^{\prime}$ positions and the $\mathrm{O}^{2-}$ ions in $\mathrm{SII}^{\prime}$ positions. This indicates the formation of oxygen-bridged dimers $\mathrm{Cd}_{2} \mathrm{O}_{2}$. As discussed earlier for the XRD experiments, the electron density located in the sodalite was labeled $\mathrm{O}(5)$, even though it is most likely due to oxygen and selenium. On the basis of the form factor for oxygen, the occupancy was calculated to be 28.9/uc. Since $\mathrm{Cd}_{2} \mathrm{O}_{2}$ dimers would account for only 11.4 oxygens, the remainder is assigned to selenium ions $(0.4 \mathrm{Se}$ per sodalite cadmium), detected by EXAFS with a bond distance Cd-Se of $2.60 \AA$. Thus, on average, the sodalite units contain two cadmium ions occupying $\mathrm{SI}^{\prime}$ positions, bridged by two oxygen ions in $\mathrm{SII}^{\prime}$ positions. An additional selenium atom in $\mathrm{SII}^{\prime}$ is bound to one 
cadmium atom (see Figure 12A,B). This arrangement can be considered as a modified fragment of the $\mathrm{Cd}_{4} \mathrm{O}_{4}$ cube found in CdY.

The remaining $\mathrm{Cd}-\mathrm{Se}$ interactions are assigned to $\mathrm{Cd}$ in SIII $(\mathrm{Cd}-\mathrm{O}=2.58 \AA)$, coordinated to one $\mathrm{Se}$ with $\mathrm{Cd}-\mathrm{Se}=2.62 \AA$. Small amounts of CdSe clusters may further be present in this sample.

Sample CDSE2. As discussed above, in CDSE2 the amount of $\mathrm{Cd}-\mathrm{Cd}$ scattering is consistent with a complete $\mathrm{Cd}_{4} \mathrm{O}_{4}$ cube arrangement similar to that in $\mathrm{CdY}$. In this sample the $\mathrm{Cd}(\mathrm{II})$ cations in $\mathrm{SI}^{\prime}$ positions are bridged by oxygen in SII' $^{\prime}$ positions to form a cube-like cluster as depicted in Figure 12C,D. Distances between $\mathrm{Cd}-\mathrm{Cd}$ and $\mathrm{Cd}-\mathrm{O}(5)$ were set to values obtained from the EXAFS analysis of this sample. The high values for the coordination numbers for $\mathrm{Cd}-\mathrm{OZ}, \mathrm{Cd}-\mathrm{O}(5)$, and $\mathrm{Cd}-\mathrm{Cd}$ indicate that a large portion of cadmium ions resides in these cube formations.

Noncoordinated Extraframework Species. As in sample CDSE1, the presence of $\mathrm{Cd}-\mathrm{Se}$ interactions in sample CDSE2 is evident from the EXAFS data. The bond distance of $2.61 \AA$ is close to the value for bulk CdSe $(2.62 \AA)$. This significant $\mathrm{Cd}-\mathrm{Se}$ and, vice versa, $\mathrm{Se}-\mathrm{Cd}$ interaction (each detecting one scattering neighbor) cannot be accounted for by a cube geometry, because even partial substitution of oxygen with Se would result in a higher coordination number of cadmium detected by selenium. This indicates that a separate $\mathrm{CdSe}$ phase is present in this sample. The observed average coordination numbers may be interpreted as due to the presence of about $25 \% \mathrm{CdSe}$ clusters (nearestneighbor coordination in $\mathrm{CdSe}$ : $\mathrm{CdSe}_{4}, \mathrm{SeCd}_{4}$ ). The remaining $75 \%$ cadmium is thus present in the $\mathrm{Cd}_{4} \mathrm{O}_{4}$ cube arrangement.

Fits on the selenium edge indicate a Se-Se scattering pair with a short bond length of 2.39 (2.37) $\AA$ for both samples in varying amounts. This bond distance is characteristic for a metal-metal bond as in trigonal selenium $(2.37 \AA)$, which forms helical chains. ${ }^{40}$ Similar chains were found in zeolites loaded with selenium vapor. ${ }^{13}$ It is suggested that small amounts of these chains are present in the samples examined here. In sample CDSE2, which contains a higher relative amount of selenium, the coordination number of Se-Se is identical with the value expected for Se chains. Since only about $25 \%$ of the selenium is accounted for by formation of $\mathrm{CdSe}$, the remnant is suggested to consist of helical selenium chains. Such chains may arise from partial oxidation of $\mathrm{H}_{2} \mathrm{Se}$ or $\mathrm{Se}^{2-}$ species during sample synthesis or preparation for analysis.

The EXAFS fit results are listed in Table II and are compared to calculated coordination numbers assuming the zeolite-encapsulated $\mathrm{Cd} / \mathrm{Se}$ moieties discussed above. Good agreement between the models and fit results is obtained.

As reported previously, comparable results have been obtained for the structure of small clusters of cadmium sulfide within the

(40) Cherin, P.; Unger, P. Inorg. Chem. 1967, 6, 1589. zeolite $\mathrm{Y}$ framework. Evidence from EXAFS and XRD analysis led to the conclusion that $\mathrm{Cd}_{4}(\mathrm{O}, \mathrm{S})_{4}$ cubes were formed inside the sodalite cages in samples with low cadmium loading. Samples of higher $\mathrm{Cd}$ content showed less $\mathrm{Cd}-\mathrm{Cd}$ scattering and contained disrupted cubes.

Cube or disrupted cube configurations have also been observed in related zeolite systems. Calligaris et al ${ }^{41}$ investigated partially hydrated cadmium-exchanged $\mathrm{X}$ zeolites and found $\mathrm{Cd}^{2+}$ in $\mathrm{SI}^{\prime}$ positions and $\mathrm{H}_{2} \mathrm{O}$ in $\mathrm{SII}^{\prime}$ sites. They proposed the existence of $\mathrm{Cd}_{4}\left(\mathrm{O}_{w}\right)_{4}$ cubes within the sodalite units. The bond distances between $\mathrm{Cd}$ and zeolite oxygens $(2.40 \AA)$ and between $\mathrm{Cd}$ and $\mathrm{H}_{2} \mathrm{O}(2.36 \AA)$ closely resemble our results.

In calcium-exchanged zeolite $\mathrm{Y}\left(\mathrm{Ca}^{2+}\right.$ and $\mathrm{Cd}^{2+}$ are comparable in their ionic radii: $0.99 / 0.97 \AA$ ), Costenoble et al. ${ }^{42}$ assumed the formation of $\mathrm{Ca}(\mathrm{OH})_{2} \mathrm{Ca}$ species after dehydration at 423-623 $\mathrm{K}$. The cations were located in $\mathrm{SI}^{\prime}$ and the $\mathrm{OH}$ groups in adjacent SII' positions, screening the charge of the neighboring calcium ions. Again, comparable bond distances between calcium and zeolite oxygen were found $(R=2.40 \AA)$.

The formation of $\mathrm{Cd}-\mathrm{Se}$ ensembles in sodalite subunits must involve diffusion of $\mathrm{H}_{2} \mathrm{Se}$ from the supercage through zeolite six-ring windows with a typical pore opening of $2.6 \AA$. The diameter of $\mathrm{H}_{2} \mathrm{Se}(2.34 \AA)$ clearly allows the diffusion to take place. The intrazeolite $\mathrm{Cd}-\mathrm{Se}$ bond distance derived from this study is close to that of bulk $\mathrm{CdSe}$ and indicates some covalent character of these species. It is likely that $\mathrm{HSe}^{-}$fragments replace the original $(\mathrm{O}(5))$ species in the precursor $\mathrm{Cd}_{4} \mathrm{O}_{4}$ cube arrangement.

In conclusion, we have investigated the generation of $\mathrm{CdSe}$ molecular clusters using both EXAFS and high-resolution synchroton powder diffraction. The use of both techniques provides complementary structural information that is invaluable in these complex host-guest systems. Powder X-ray diffraction data give the average structure while EXAFS is a more local probe of environment. The structures can be explained by zeolite-stabilized, cube-like $\mathrm{Cd}_{4} \mathrm{O}_{4}$ clusters or $\mathrm{Cd}_{2} \mathrm{O}_{2} \mathrm{Se}$ fragments occupying the sodalite units and additional $\mathrm{CdO}_{2} \mathrm{Se}$ fragments at SIII positions. Noncoordinated helical selenium chains and a small fraction of $\mathrm{CdSe}$ are formed primarily in the sample with a higher $\mathrm{Se} / \mathrm{Cd}$ ratio.

Acknowledgment. Support provided by the Sandia-University Research Program (DOE; T.B.) and ONR (G.D.S.) is gratefully acknowledged. The operational funds for NSLS beam line X-11A are supported by DOE Grant No. DE-ASO580ER 10742. The technical assistance of J. E. MacDougall and J. B. Jensen is gratefully appreciated.

(41) Calligaris, M.; Nardin, G.; Rancaccio, L.; Zangrando, E. Zeolites $1986,6,439$.

(42) Costenoble, M. L.; Mortier, W. J.; Uytterhoeven, J. B. J. Chem. Soc., Faraday Trans. 1 1978, 74, 466. 